\title{
ORIGINAL
}

\section{Environmental Radioactivity Monitoring in Taiwan in the Period 1974-1978}

\author{
Yu-Ming LIN, ${ }^{*, * 1}$ Mei-Fung Chang, ${ }^{* *, * 1}$ \\ Yu-Chia Shen***,*1 and Pao-Shan WenG****,*2
}

(Received January 31, 1979)

An islandwide network for environmental radioactivity monitoring established in the Taiwan Province of the Republic of China in 1974 to provide radiation base line data for the government agencies, was described with reference to types of environmental samples taken and types of radioactivity monitored. Both gammaray spectroscopy and radiochemical methods were used to detect fission products and naturally occurring radionuclides in all environmental samples. Emphasis was placed on the analysis of long-lived fission products such as ${ }^{90} \mathrm{Sr}$ and ${ }^{137} \mathrm{Cs}$. A special feature of the monitoring network is to analyze the fission products in diet of children which is a special nutritious lunch program for the primary school children. Relatively high activity from nuclear testing at Lop Nor during 1974-1978 is indicated with corresponding dates and sequence number of tests.

KEY WORDS: environmental monitoring, natural radioactivity, fallout radioactivity, Taiwan, gamma-ray spectrometry, radiochemical analysis, strontium-90, cesium-137, fission products, Lop Nor Test.

\section{INTRODUCTION}

The Taiwan Radiation Monitoring Station (TRMS) of Atomic Energy Council (AEC) of Executive Yuan has a primary responsibility to establish the radiation baseline data for the government agencies in the Republic of China (ROC) since its inception in 1974. One of the TRMS's mandates in carrying out this responsibility is to monitor the environmental radioactivity from all sources in Taiwan, both manmade and natural radiation sources.

This paper is part of the TRMS's environmental monitoring program. Special emphasis was placed on acquiring and summarizing the most recent

* 林友明, ** 張美風, *** 沈于嘉, $* * * *$ 翁宝山

*1 Taiwan Radiation Monitoring Station, Atomic Energy Council of Executive Yuan; Ta-Hwa village, Kaoshiung Hsien, Taiwan 833, Republic of China. 台湾輻射偵測工作站行政院原子能委員会;台潜省高雄 県大華村，中華民国

*2 Health Physics Division, National Tsing-Hua University; Hsinchu, Taiwan 300, Republic of China.

国立清華大学保健物理組, 台湾省新竹市, 中華民国 data obtained and available. An effort was made in this paper to identify source categories of radiation, particularly from radioactive fallout due to nuclear testing at Lop Nor $\left(40^{\circ} \mathrm{N}, 90^{\circ} \mathrm{E}\right)$.

Special effort was made in this paper to acquire data from TRMS's laboratories located at Kaoshiung Hsien in the southern part of Taiwan. The TRMS obtains environmental samples from its own islandwide networks and involves the analysis of samples of air, soil, vegetation, water, food, etc.

The nuclear testings held at Lop Nor of mainland China during the monitoring period were on the following days based on official announcements and statements in open publications:

Dates of Test

June 17, 1975

Test Sequence No.

October 27, 1975

16

January 23, 1976

17

18

September 26, 1976

October 17, $1976 \quad 20$

November 17, $1976 \quad 21$

September 17, 1977

March 15, 1978

December 14, $1978 \quad 24$ 
All figures presented in this paper will be indicated with corresponding date and sequence number of the nuclear testings.

\section{EXPERIMENTAL}

The environmental samples collected routinely and periodically from the TRMS's islandwide networks were analyzed as below:

1) gross beta activity,

2) ${ }^{90} \mathrm{Sr},{ }^{137} \mathrm{Cs}$, and naturally occurring radionuclides,

3) gamma-ray spectroscopy, and the samples were categorized as:

1) air dust by gummed film and water tray,

2) water including saline, non-saline, and rain,

3) vegetation mainly grass,

4) food including milk, fruits, wheat, vegetables, eggs, fish, potatoes, ducks, chicken, pork, rice, tea, and student lunch,

5) soil including surface and at $10 \mathrm{~cm}$ depth.

The sampling techniques have long been well established in Taiwan, and the pretreatment was either wet ashing or non-wet ashing depending on the type of samples involved.

The gross beta activity was measured with a low background counting system. The counting rate obtained was corrected for counter efficiency, geometry, backscatter, and self-absorption using appropriate standards such as potassium chloride (KCl).

The gamma-ray spectroscopy for prepared samples was measured by use of a 4,096-channel pulse height analyzer coupled with a well-shielded $\mathrm{Ge}(\mathrm{Li})$ detector and mini-computer.

The radiochemical methods involved were for ${ }^{90} \mathrm{Sr}$ and ${ }^{137} \mathrm{Cs}$ analysis. The procedures are as follows:

Strontium-90: Biological samples were solubilized according to the method developed in Taiwan, and yttrium was separated by exchange and counted. ${ }^{11}$

Cesium-137: Cesium was separated first on AMP and then purified by the combined dipcrylaminate-chloroplatinate-method.

Voluminous data have been obtained during the last four years. However, the significant ones only will be presented here according to types of environmental samples and types of radioactivity as well.

1. Air

a) Gross beta activity in upper and surface air by sampler

The activity in upper air was detected along domestic commercial aircraft (Boeing 727 and 737)

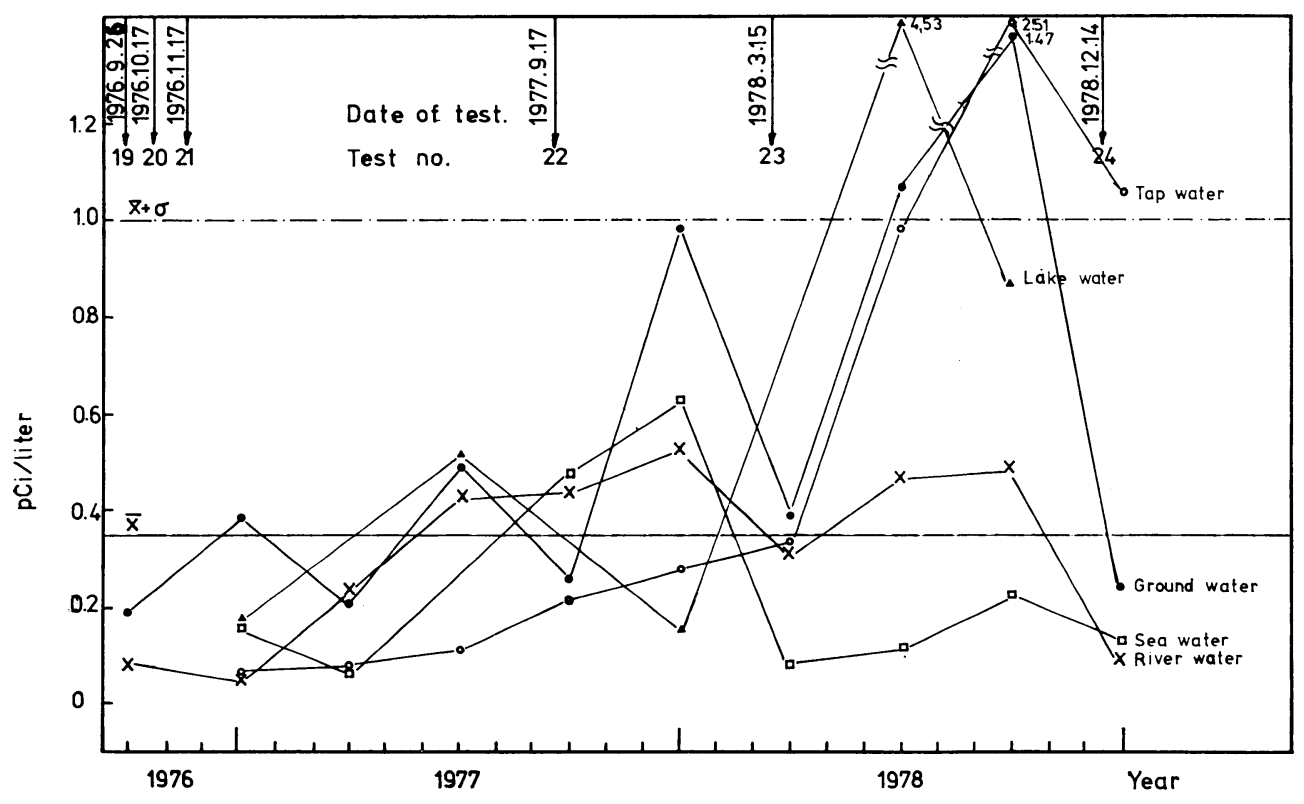

Fig. 1 Concentration of ${ }^{90} \mathrm{Sr}$ in surface water. 
Environmental Radioactivity Monitoring in Taiwan in the Period 1974-1978

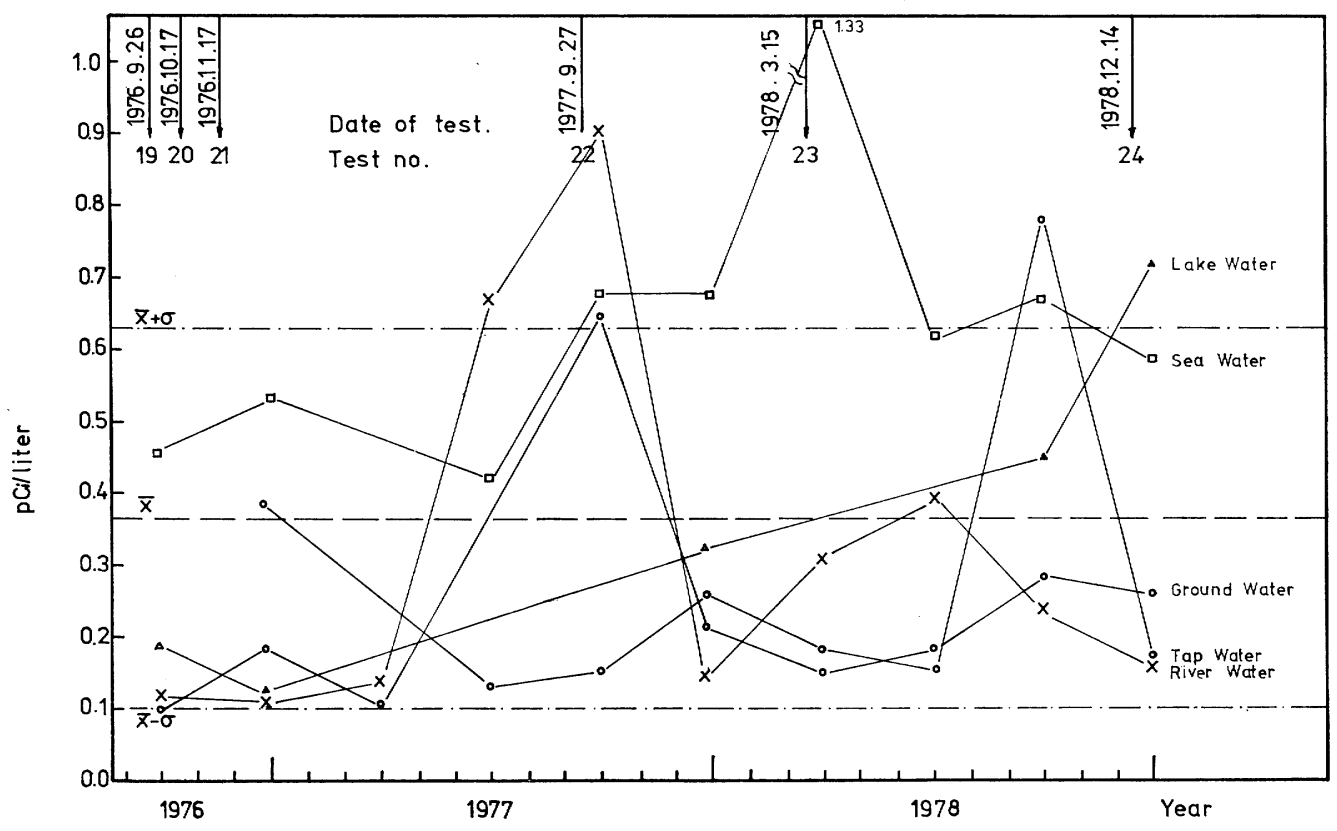

Fig. 2 Concentration of ${ }^{137} \mathrm{Cs}$ in surface water.

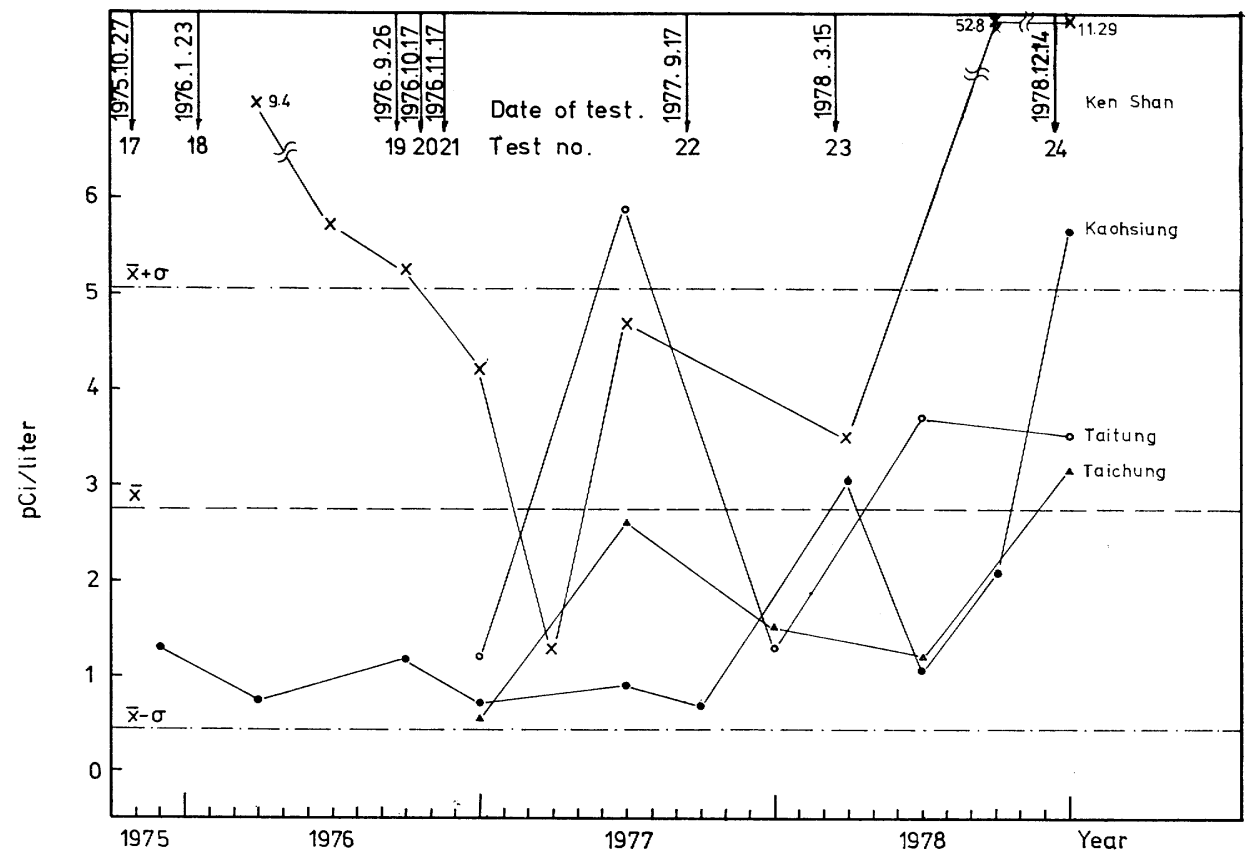

Fig. 3 Concentration of ${ }^{90} \mathrm{Sr}$ in milk. 


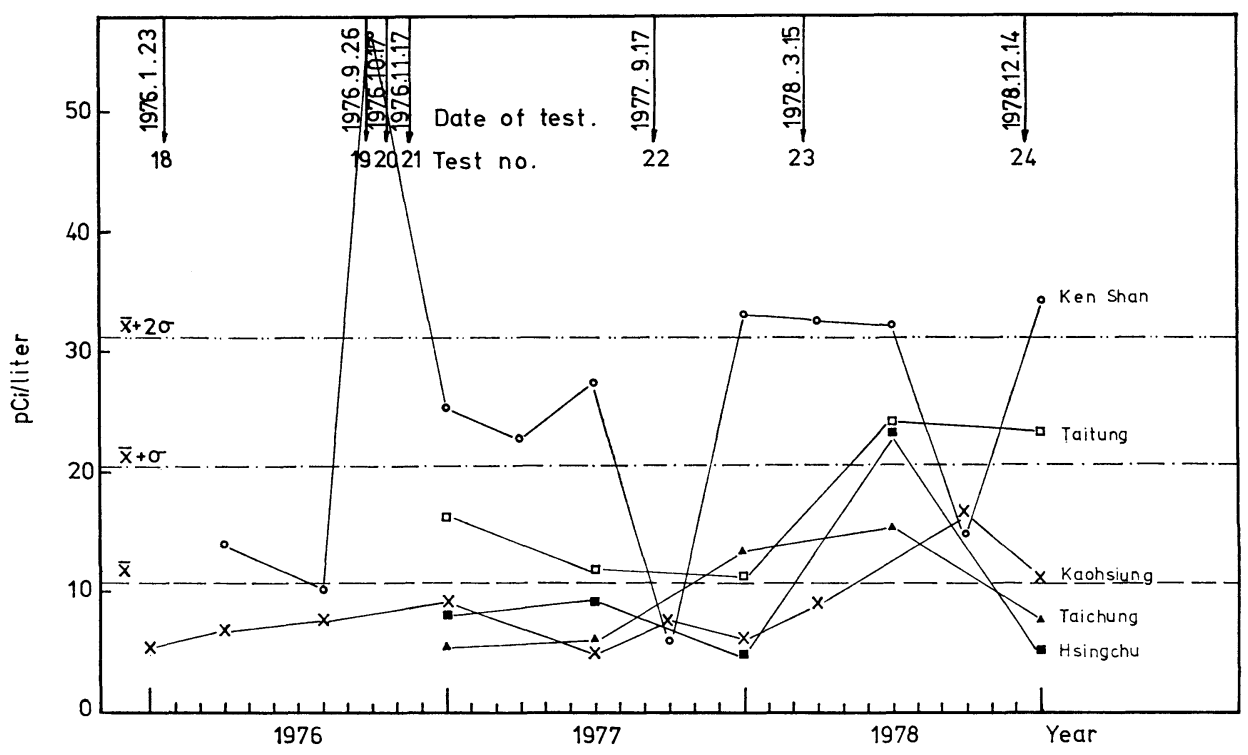

Fig. 4 Concentration of ${ }^{137} \mathrm{Cs}$ in milk.

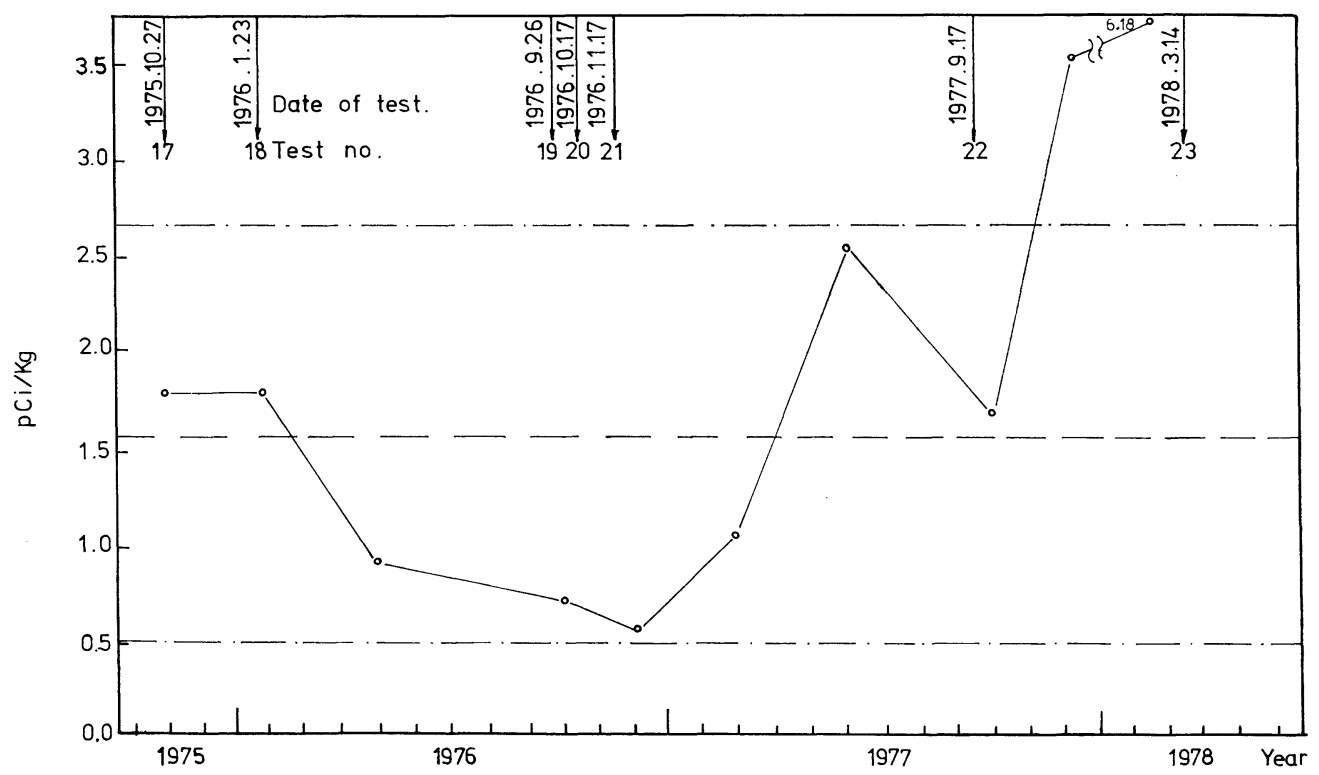

Fig. 5 Concentration of ${ }^{90} \mathrm{Sr}$ in diet of children.

flights routes between Taipei and Kaohsiung. Sampling positions were chosen from representative areas most likely to have contamination debris embedded on their surface.

b) Gross beta activity in surface air by gummed film. c) Gross beta activity in surface air by water tray.

Of the methods mentioned above, gummed film methods prove to be the simplest and most efficient one by our experience as far as gross beta measurements are concerned. However, improve- 
ments are needed to keep the water out of the film during rain, otherwise the fallout be washed out and no activity can be detected.

\section{Water}

The concentrations of ${ }^{90} \mathrm{Sr}$ and ${ }^{137} \mathrm{Cs}$ in surface water including both saline and non-saline are shown in Figs. 1 and 2 where samples were taken throughout Taiwan and the results shown here are the average concentrations from several samples.

\section{Vegetation}

The gamma-ray spectrum of grass after the 21st nuclear testings at Lop Nor shows that fission products such as ${ }^{141,144} \mathrm{Ce},{ }^{103} \mathrm{Ru},{ }^{95} \mathrm{Zr}-{ }^{95} \mathrm{Nb}$ are present. The age of the fission products can be identified approximately by using the ratio of ${ }^{95} \mathrm{Zr}$ and ${ }^{95} \mathrm{Nb}$.

\section{Food}

The concentration of ${ }^{90} \mathrm{Sr}$ and ${ }^{137} \mathrm{Cs}$ in milk from several sampling stations are shown in Figs. 3 and 4. The concentration of ${ }^{90} \mathrm{Sr}$ in diet of children is shown in Fig. 5. The latter is particularly interested since the school lunch program is a special project to provide the primary school children with a nutritious lunch containing flour products as the main course.

The flour products are made primarily from imported wheat. It is contrary to the diet of adults who prefer to have rice for their lunch.

\section{Soil}

The gross beta activity in surface soil of $0 \sim 10$ $\mathrm{cm}$ depth taken from several sampling stations has been measured and the gamma-ray spectrum as well. The naturally occurring radionuclides do appear except the long-lived fission product ${ }^{137} \mathrm{Cs}$ which also appears.

All data reported in this paper are in good consistence with previous investigations. ${ }^{2-14)}$ Though Taiwan is not the main pathway for the fallout from nuclear tests held at Lop Nor, the fallout can still reach Taiwan in some of the nuclear tests as shown in the figures listed above. In addition to radioactivity monitoring in the network, radiation monitoring using thermoluminescent dosimeters (TLD) has already started in each monitoring station since 1977. The whole network will serve as an environmental radiation protection medium for the ROCAEC and the general public as well with the cooperation of National Tsing Hua University, Taiwan Power Company, and Institute of Nuclear Energy Research. The estimation of the population dose based on present data is in- significant.

Acknowledgements: The authors wish to thank Professor Chen-Haw Cheng, Secretary General of ROCAEC, for his constant encouragement and guidance. The authors also wish to thank Mr. Ming-Te Chou and Mr. Tieh-Chi Chu of National Tsing Hua University for their kind assistance during the preparation of this manuscript.

\section{REFERENCES}

1) T.Y.Wu, C.N. Hsu, C.L. WANG and P.S. WeNG; Strontium-90, Cesium-137, and Iodine-131 Levels in Powdered Milk, Nucl. Sci. J., 13, 112 (1975).

2) T.C. Chu, C.H. Cheng and P.S. Weng; A Survey of Strontium-90 and Cesium-137 Concentrations in Taiwan Tea, Hoken Butsuri, 4, 514 (1969).

3) W.S. LiU, T.C. Chu and P.S. WeNG; Measurement of Strontium-90 and Cesium-137 in Milk, Hoken Butsuri, 5, 195 (1970).

4) P.S. Weng, C.M. Tsai and C.H. Cheng; Fallout over Taiwan from Nuclear Weapon Tests at Lop Nor and Siberia (1958-1969), Health Phys., 19, 563 (1970).

5) P.S. Weng and C.N. Hsu; Strontium-90 and Cesium-137 Levels in the Diet of Children on a School Lunch Program, Radiol. Health Data Rep., 12, 139 (1971).

6) P.S. Weng, C.M. Tsai, S.J. Su, C.Y. Huang and T.C. CHU; Background Activity of Taiwan, Hoken Butsuri, 6, 131 (1971).

7) P.S. Weng and P.L. Liu; Strontium-90 and Cesium-137 in Ganned Seafood, Taiwan, Republic of China, 1970-1971, Radiol. Health Data Rep., 12, 25 (1971).

8) P.S. WenG, C.M. Tsai and T.C. Chu; Environmental Radioactivity and Radiation Measurements in Taiwan, Republic of China, The Natural Radiation Environment II, CONF-720805-P1, 375 (1972).

9) P.S. WeNG, T.C. Chu and C.M. TsaI; Environmental Radioactivity in North Taiwan, Health Phys., 25, 123 (1973).

10) P.S. Weng; The Preoperational Environmental Radioactivity Surveillance Program for the First Nuclear Power Plant in Taiwan, International Symposium on Nuclear Technology and Economics, Taipei, 13-20 January (1975).

11) P.S. Weng; Experiences Gained During the Preoperational Environmental Radioactivity Surveillance Period for the First Nuclear Plant in Taiwan, Nat. Sci. Council Monthly, 4, 44 (1976).

12) P.S. WeNG; On the Environmental Radioactivity 
Surveys for the Nuclear Facilities; Eng. J., 50, 51 (1977).

13) P.S. Weng, Y.C. Hsu, C.N. Hsu and S.J. Su; Detection of Hot Fallout on Taiwan in the Period 1971-1975, Health Phys., 33, 241 (1977).

14) P.S. Weng, Y.M. Lin and T.C. Chu; Measure- ment and Monitoring of Radioactivity in Aquatic Environment Including Precipitation on Taiwan, Colloquium on Aquatic Environment in Pacific Region, Academia Sinica, Taipei, 21-23 August (1978). 